Kaplan, B. (1942): Hematemesis due to Rupture of an Aortic Aneurysm: Report of a Case, New Engl. F. Med., 226, 984.

Koppisch, E. (1933): Clinico-Pathological Analysis of Interesting Cases, Bol. Asoc. méd. P. Rico., $25,140$.

Krudy, A. G., and Smith, J. A. (1955): Multiple Saccular Aneurysms of the Thoracic Aorta with Spontaneous Rupture into the Esophagus: Report of a Case, Dis. Chest., 27, 690.

Lemann, I. I. (1916): A Study of Thoracic Aneurysm, Amer. F. med. Sci., r52, 210.

Lucke, B., and Rea, M. H. (i 923): Studies on Aneurysm, II-Aneurysm of the Aorta, f. Amer. med. Ass., 81, i 167.

Lutembacher, R. (1949): Aneurysmes de L'Aorte: Infiltration et Rupture dans les Parois de L'CEsophage, Presse Medicale, 57, 857.

Osler, W. (1909): Syphilis and Aneurysm, Brit. med. F., ii, I 509.

Ramseyer, M. (1956): Perforation dans L'CEsophage d'un Aneurysme Disséquant de l'Aorte, Radiol. Clin., 25, 297.

Spearman, M. ( 1 936): Traumatic Aneurysm of Arch of Aorta with Rupture into Esophagus, Southwest Med., 20, 174.

Watanabe, T., and Usuku, S. (1936): Ein Fall von Aortenaneurysma mit Einer Broncho-Esophagealfistel, Nagasaki Igakkai Zasshi, 14, 520.

\title{
THROMBOSIS-IN-SITU OF THE MAIN PULMONARY ARTERIES
}

\author{
T. A. Don Michael, M.B., M.R.C.P. (Lond.), M.R.C.P. (Edin.). \\ Registrar, St. Stephen's Hospital, London, S.W.10
}

MASsive thrombotic occlusions of the main pulmonary arteries is a rare condition occurring perhaps once in five thousand post-mortem examinations. Its clinical recognition is even rarer (Magidson and Jacobson, I955). Posselt (I909) could find only three examples of complete occlusions of the pulmonary artery in its main branches, and Brenner (1931), six cases of organizing thrombus in the main pulmonary arteries.

\section{Case Report}

F.M.L., 5 I-year-old female patient, was admitted to Guy's Hospital on $4.5 .6 \mathrm{I}$ with a history of progressive breathlessness and palpitations of four years' duration. A heart murmur had been heard at the age of 7 but although she attended a special school she had led a normal life up to the age of $4 \mathrm{I}$. She then sustained an injury to her left leg and had suffered from recurrent swelling in it since. She also suffered accidental injury to the front of her chest and thereafter complained of pain in the chest. For the past ten years she had noticed gradually increasing breathlessness and occasional palpitations and suffered from frequent chest colds. Prior to admission her breathlessness was of such a degree that she was confined to bed.

Examination revealed a thin patient with cyanosed mucous membranes and early clubbing of the fingers. The jugular venous pressure was raised $4 \mathrm{~cm}$. above the sternal angle and well marked ' $a$ ' and ' $v$ ' waves were present. The apex beat was in the 6 th space $I$ in. outside and the mid-clavicular line and was diffuse in character. There was a moderate left parasternal pulsation. A pansytolic murmur was audible at the apex and left sternal edge with a soft ejection murmur in the pulmonary area. The second sound in the pulmonary area was accentuated and rather widely split. 'There were no abnormal physical signs present in the respiratory system. 'The liver was palpable, I finger's breadth below the costal margin.

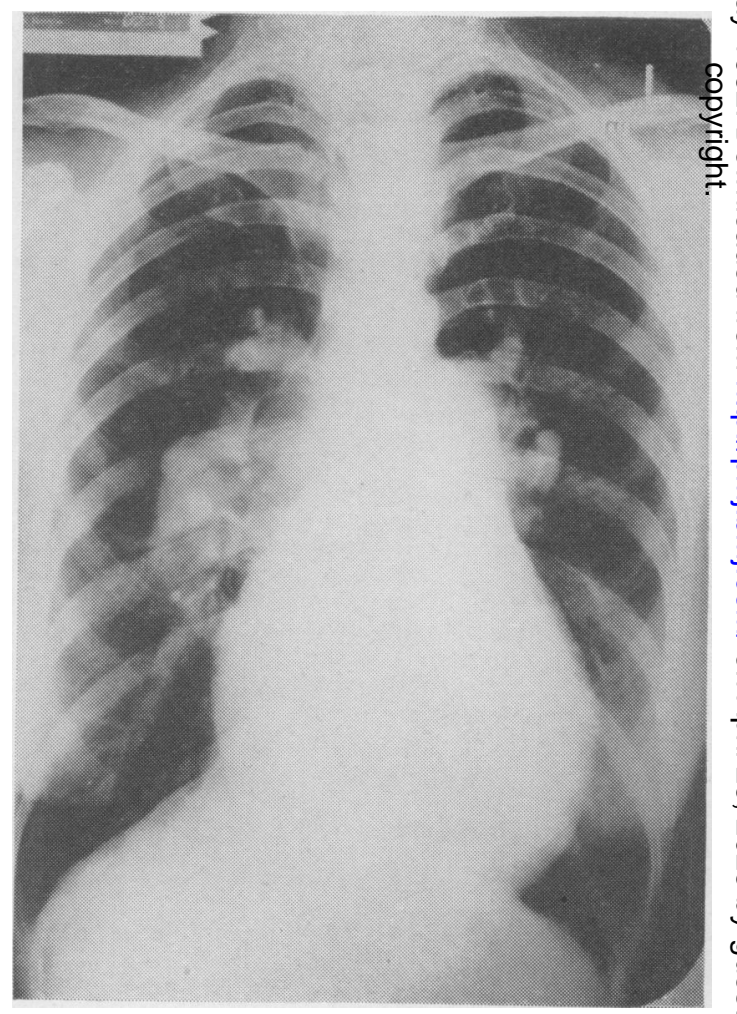

FIG. I

'I'here was no peripheral cedema present and no tenderness over the deep veins of the legs. 


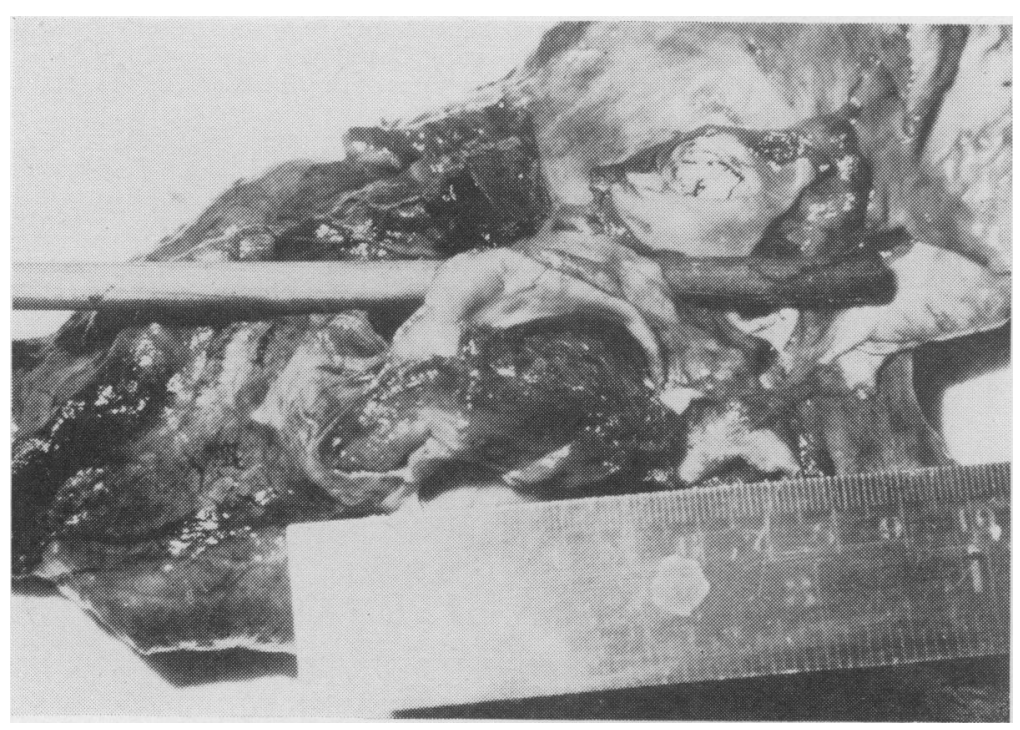

FIG. 2

Investigations. Radiography revealed generalized cardiac enlargement with large pulmonary trunks and pruning laterally of the pulmonary vasculature such that the peripheral lung fields were oligæmic (see Fig. I). Screening confirmed these findings and showed increased pulsations in the pulmonary arteries with some enlargement of the left as well as the right ventricle. Electrocardiography showed right ventricular hypertrophy with incomplete right bundle branch block and a $\mathbf{P}$. Pulmonale. At cardiac catheterization the pulmonary artery pressure was $88 / 36$ with a pulmonary vascular resistance of 12 units. The catheter figures indicated a shunt at atrial level with a calculated systemic flow of $3.4 \mathrm{l}$./min., a pulmonary flow of $4.1 \mathrm{l} / \mathrm{min}$. giving an L-R shunt of $1.31 . / \mathrm{min}$. and an R-L shunt of $0.61 . / \mathrm{min}$. The catheter could be passed into a pulmonary vein from both the superior vena cava and the right atrium indicating anomalous venous drainage through independent inlet foraminæ from virtually the whole of the right lung. A large defect was thought to be present at atrial level. The catheter could not be wedged in the medial branches of the right pulmonary artery and obstruction by a thrombus was suspected. Dye dilution studies indicated a bidirectional shunt at atrial level. The phonocardiogram confirmed the presence of a pansystolic murmur at the apex and left sternal edge. There was wide splitting of the second sound in the pulmonary area $(0.5 \mathrm{sec}$.).

$\mathrm{Hb}, 89 \%$; w.b.c., 4,000/cu. mm.; (polymorphs, $55 \%$; lymphocytes, $40 \%$; monocytes, $2 \%$; eosinophils, 3\%). Electrolytes: $\mathrm{Na} \mathrm{I}_{35}, \mathrm{~K}{ }_{5}, \mathrm{Cl}_{\mathrm{I}} \mathrm{O2}, \mathrm{HCO}_{3}$ I $9 \mathrm{mEq} . / 1$.

On the basis of these findings the clinical diagnosis was:

1. Atrial Septal Defect. Presumably large with a bidirectional shunt, predominantly L-R,

2. Pulmonary Hypertension. Probably accounted for by the atrial septal defect but possibly aggravated by thromboembolism in the pulmonary arteries. There was evidence of right-sided cardiac failure.

3. Suspected Thrombosis of Right Pulmonary Artery. 4. Anomalous Venous Drainage. From the whole of the right lung opening independently into S.V.C. and
R.A.

5. Paroxysmal Supraventricular Tachycardia.

She was thought unsuitable for surgical treatment and $\overrightarrow{0}$ treated with digoxin $0.25 \mathrm{mg}$. daily.

Her final admission was as an emergency to Stephen's Hospital, Chelsea, on 26.ro.6r. She presented with severe breathlessness and cyanosis. Her apex rate was $150 / \mathrm{min}$. otherwise physical signs and chest $\mathrm{X}$-ray were unchanged. The electrocardiograph showed and atrial tachycardia of $150 / \mathrm{min}$. with changes similar to $\frac{0}{\mathrm{D}}$ those described previously. Carotid compression had no effect on the heart rate and the patient was given $\overrightarrow{\vec{F}}$ digoxin $0.25 \mathrm{mg}$. orally. Approximately six hours after admission she was still very breathless and cyanosed with a heart rate of $150 / \mathrm{min}$. and it was decided to treat her with quinidine. After the first dose of gr. Io the heart rate slowed to $100 / \mathrm{min}$. and the drug was repeated in two hours. Soon after, the patient suddenly 3 collapsed and died. Cardiac massage by the externali route was performed without success, although a 3 palpable femoral pulse was obtained at each stroke.

Autopsy. The body was that of a thin middle-aged 0 woman with early clubbing and deep cyanosis. The heart weighed $490 \mathrm{~g}$. and showed gross enlargement of $\mathrm{O}$ the right ventricle with plaques of subendocardial fibrosis. There were sub-pericardial hæmorrhages at $\frac{D}{O}$ the apex over the left ventricle. The tricuspid ring was considerably enlarged. The main pulmonary artery and its main branches were markedly dilated and $\sigma$ showed early atheroma. A large ante-mortem thrombus $N$ was seen in the opening of the left pulmonary artery. The lumen of both main pulmonary arteries were $\omega$ virtually occluded by two massive ante-mortem thrombi. These took the shape of the main pulmonary arteries and the thrombus in the left main pulmonary artery was adherent to the vessel wall at one point (Fig. 2). $\mathbb{\complement}$ There was fairly large septum-secundum-type, atrial $\stackrel{\text { ? }}{+}$ septal defect. There was heavily blood-stained fluid 0 in the left pleural cavity and collapse of the left lower $\bar{D}$ lobe. The brain was slightly cdematous. The $\frac{\vec{\Phi}}{\mathscr{D}}$ abdominal viscera showed passive congestion. Femoral $\frac{\rho}{\mathbb{Q}}$ 
and iliac veins were normal. Microscopy revealed intimal proliferation in medium-sized pulmonary arteries such that their lumen were grossly reduced. The thrombus was composed of fibrin and red cells. There was no evidence of organization suggesting that thrombosis was probably terminal.

\section{Pathological Diagnosis}

I. Atrial septal defect of secundum type.

2. Massive ante-mortem thrombosis of both pulmonary arteries.

3. Tricuspid incompetence and right ventricular hypertrophy.

\section{Discussion}

The unfavourable event in the natural history of this patient's illness was the development of progressive breathlessness after the fourth decade. This and her terminal illness have their background probably in the development of progressive pulmonary hypertension and terminal massive thrombosis-in-situ of her main pulmonary arteries, respectively. It would seem that the single factor altering the prognosis in patients with atrial septal defects is the development of pulmonary hypertension. Wood, discussing the evolution of the changes in the pulmonary circulation, drew attention to the precipitous fall in the pulmonary vascular resistance at birth corresponding with expansion of the lung and unfolding of its vascular tree (Dawkes, 1959). He pointed out that the closure of the ductus arteriosus is followed by insulation of the pulmonary circulation from systemic pressures and as a result, involutionary changes occur in the pulmonary arterioles (Edwards, 1957). This leads to a more gradual fall in the pulmonary vascular resistance. The presence of a large shunt would be expected to interfere with these changes. For this to happen shunts need to be of the order of $I_{5}$ to 201 . In such cases the adaptive dilatation of the pulmonary vascular tree is exceeded and hyperkinetic pulmonary hypertension results. With shunts at ventricular or aorto-pulmonary levels, a situation akin to that of the fœtal pulmonary circulation exists (Goodwin, 1960). In interatrial shunts, however, there is usually a time-lag of several decades. The reasons for this are not very clear. Where pulmonary hypertension develops, however, it tends to be self-perpetuating. Several factors may contribute to this, such as: thromboembolism in the pulmonary tree; right-sided heart failure; polycythæmia; atheroma in pulmonary arterioles; atrial tachycardia and fibrillation. These factors moreover are inter-related and establish a vicious circle leading to progressive vaso-occlusive pulmonary arterial disease and hypertension.

This patient was symptom free for four decades, and a year before her death had developed quite considerable pulmonary hypertension. However, she cannot be classed in the Eisenmenger syndrome because she had a significant L-R shunt (Goodwin, 1960). The catastrophe that led to her death is rare as a primary event (Daley, I960). It was probably precipitated by the atrial tachycardia she developed at her final admission. However, thrombosis in her main pulmonary arteries may have been present for several years until fresh occlusion proved fatal, so that the condition cannot be considered as purely terminal. Indeed thrombosis in her right pulmonary artery was suspected at her previous admission, although pulsation thereof detected at fluoroscopy would seem to point against this. The history of chest trauma is significant in that non-penetrating chest injury has been previously described as a possible contributory cause of pulmonary thrombosis (Dimond and Jones, 1954). The history of recurrent swelling in the injured leg may be taken as evidence of deep venous obstruction; a possible source of pulmonary emboli. However, it is more than possible that primary thrombosis of the main pulmonary arteries had developed in the view of the long standing pulmonary hypertension and atherosclerosis (Wood, 1956).

Several cases have been described in the literature (Ball, Goodwin and Harrison, 1956; and Ring and Bakke, 1955). These have been associated with mitral stenosis, large L-R shunts and long standing pulmonary hypertension. Rarer conditions thought to be responsible include polycythæmia rubra vera (Poll, 1935), syphilitic lesions of the pulmonary arteries (Cheney and Clarke, 1927) and tumours of the lung (Brenner, 1931).

The clinical picture is of progressive deterioration in effort tolerance with signs of right-sided heat failure. Effort syncope, substernal or abdominat. pain, cough, hæmoptysis, mental confusion, als $\hat{\theta}$ blurred vision, exophthalmos and conjunctival congestion (Savacool and Charr, 194I) may be the presenting features. In patients with previously known L-R shunts, reversal may occur. Despite quite severe occlusion pulmonary infarction does not follow as a rule.

With regard to treatment, surgery did not have anything to offer as far as closure of the defect. Dammann and Ferencz, recognising the protective influence of right ventricular outflow obstruction in progressive pulmonary hypertension, have adopted the practice of producing pulmonary stenosis artificially. The question arises whether anticoagulant therapy can be used. Wood, however, considers their use fraught with the risk of hæmoptysis in patients with large shunts. Therefore, treatment is confined to prevention and correction of heart failure and management of associated supraventricular tachycardia. The prognosis in cases where thrombosis of pulmonary arteries has occurred is unfavourable, the majority run a subacute course which is eventually fatal (Magidson and Jacobson, 1955).

\section{Summary}

A case is reported of a woman of $5 \mathrm{I}$ with an atrial $\stackrel{D}{\mathcal{D}}$ septal defect whose symptoms started ten years previously and worsened progressively until her death. She had considerable pulmonary hypertension with shunt reversal and right-sided heart .

\section{.}

.

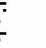

.

.

.

年
政

\section{.}

\section{.} . O D 政 の \% ֻ 
failure, and thrombosis of the right main pulmonary artery was suspected during life. At post-mortem, there was massive thrombosis-in-situ of her main pulmonary arteries.
My thanks are due to Sir Russell Brock and Dr. p을 Harvey for permission to publish this case report; alscå to Dr. R. Daley for his helpful advice and criticismsz

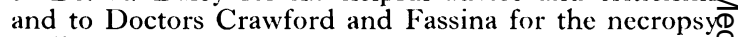
findings.

\title{
REFERENCES
}

Ball, K. P., Goodwin, J. F., and Harrison, C. V. (1956): Massive Thrombotic Occlusion of Large Pulmonaryo Arteries, Circulation, 14, 766.

Brenner, O. ( 1931 ): Sclerosis of the Pulmonary Artery with Thrombosis, Lancet, ii, 91 I.

Cheney, G., and Clarke (1927): Ayerza's Disease: with a report of two cases, Amer. F. med. Sci., 174, 34.

Daley, R., in Daley, R., Goodwin, J. F., and Steiner, R. E., Ed. (1960): Clinical Disorders of the Pulmonary Circulation, p. 270. London: J. \& A. Churchill.

DammanN, J. F., Jr., and Ferencz, C. (1956): Significance of Pulmonary Vascular Bed in Congenital Heart Disease Defects between Ventricles or Great Vessels in which Both Increased Pressure and Blood Flow may act upon $\vec{\circ}$ Lungs and in which there is Common Ejectile Force, Amer. Heart F., 52, 210.

Dawes, G. S., in Adams, W. R., and Veith, I., Ed. (1959): Pulmonary Circulation, p. 270. New York: Grune $\alpha_{\vec{\omega}}$ Stratton.

Dimond, E. G., and Jones, T. R. (1954): Pulmonary Artery Thrombosis Simulating Pulmonic Valve Stenosis witho Patent Foramen Ovale, Amer. Heart F., 47, 105.

Evwards, J. E. (1957): Functional Pathology of the Pulmonary Vascular Tree in Congenital Cardiac Disease, Circulation, 15,164 .

Goodwin, J. F., in Daley, R., Goodwin, J. F., and Steiner, R. E., Ed. (ig60): Clinical Disorders of the Pulmonary Circulation, p. 270. London: J. \& A. Churchill.

Magidson, O., and Jacobson, G. ( 1 955): Thrombosis of Main Pulmonary Arteries, Brit. Heart f., I7, 207.

Poll, D. (1935): Thrombosis of Pulmonary Vessels in Polycythæmia Vera, f. Mount Sinai Hos., I, 254.

Posselt, A. (1909): Die Erkrankungen der Lungenschlagader, Ergebn. allg. Path. Path. Anat., 13, 298.

Ring, A., and BAKke, J. R. (1955): Chronic Massive Pulmonary Artery Thrombosis, Ann. Intern. Med., 43, 78I.

Savacool, J. W., and Charr, R. (194I): Thrombosis of Pulmonary Artery, Amer. Rev. Tuberc., 44, 42.

Wood, P. (1956): Diseases of the Heart and Circulation, p. 832. London: Eyre and Spottiswoode.

, P. (1958): The Eisenmenger Syndrome, or Pulmonary Hypertension, with Reversed Central Shunt, Brit med. $\mathcal{F} ., 2,701,755$.

\section{CARCINOID SYNDROME WITH UNUSUAL FEATURES}

\author{
M. A. Hossain, M.B., B.S., F.R.C.S. (Edin.), F.R.C.S. (EnG.) \\ Formerly Surgical Registrar, The Royal London Homoopathic Hospital, Great Ormond Street, London, W.C.I
}

Carcinoli tumours arise from specialized epithelial cells (Kuschitsky cells) of the gastrointestinal tract. These cells can secrete 5 -hydroxytryptamine (5-HT) and an excessive quantity of this substance produces a remarkable syndrome in patients suffering from metastasizing carcinoids with atypical cyanosis, flushing, diarrhœa, asthma-like attacks and, in the late stages, valvular diseases of the right side of the heart (Biörck, Axen and Thornsen, 1952 and Thornsen, Biörck, Bjorkman and Waldenstrom, I954).

The bizarre and inconstant nature of the symptoms can lead to diagnostic error as happened in the following case, the diagnosis of which was not established during life.

\section{Case Report}

A 67-year-old taxi-driver, previously in good health, had a 'heart attack' in 1958 and 'chest trouble' in April, 1959. In August, 1959, while driving, he fainted, hit a car ahead and received head injuries for which he was treated in the hospital. On examination his abdonen was found to be tense and rigid. All other clinical and relevant laboratory findings were within norma잉 limits.

In 1960, from May to July, he was investigated foi loss of weight, intermittent back and abdominal pain, episodic diarrhoea and poor urinary stream. Examination revealed periodic increase of muscle tone. At no time was the urinary excretion of 5-hydroxy-indole acetic acid in the urine determined.

On October 4, 1960, he was admitted with retention of urine due to the enlarged prostate. His prostate waso removed and he had no complications from the operation. During the post-operative period some curious symptoms appeared. He had a brief attack of wheezing and respiratory distress similar to asthma. His face ${ }^{N}$ which was permanently red with telangiectases on thळ cheek and nose, showed unusual changes of colour, i.e. flushing with vivid redness, patches of cyanosis on a re background and blanching. A peculiar mental change was observed. $\mathrm{He}$ was slow to speak and answer questions, his face dull and expressionless. He showed limited movements and activity. Occasionally he lay in bed motionless, completely withdrawn from his sur roundings. He would stand with body slightly flexed his gait was slow with short steps not unlike that of Parkinsonism. 'There were no tremors. Sensation anct 